Article

\title{
Five William Shakespeares Versus One Santa Claus; Self-Sacrifice and The Trolley Problem in the Series "The Good Place"
}

\author{
Frank G. Bosman \\ Tilburg Cobbenhagen Center, Tilburg University, 5037 AB Tilburg, The Netherlands; \\ f.g.bosman@tilburguniversity.edu
}

Received: 18 June 2020; Accepted: 13 July 2020; Published: 17 July 2020

\begin{abstract}
The television series The Good Place (2016-2020), created by Michael Schur revolves around four humans who-after their deaths—end up in what they believe to be heaven: the "Good Place". In reality, however, they are in a very sophisticated torture place, built and directed by demons from the "Bad Place". During the four seasons of the series, the four humans discover the true nature of their predicament and try to reach to "real" Good Place, through-among other means-improving their moral attitude, e.g., becoming a better person by taking ethical lessons provided by one of the four, who is an actual professor of moral philosophy. During these lessons, the four discuss many ethical and philosophical notions, ideas and problems, among which is Philippa Foot's famous 1967 thought experiment known as the Trolley Problem. The series as a whole, the author of this article argues, revolves around this impossible moral dilemma, suggesting self-sacrifice as an ultimate solution to the Trolley Problem.
\end{abstract}

Keywords: The Good Place; sitcoms; Trolley Problem; Philippa Foot; ethical dilemma; self-sacrifice

This is an exciting day. We are going to tackle The Trolley Problem. ( ... ) You are driving a trolley when the brakes fail, and on the track ahead of you are five workmen that you will run over. Now, you can steer to another track, but on that track is one person you would kill instead of the five. What do you do?

This quote sounds like it has been taken from a textbook on moral philosophy, or maybe a scene from a university classroom somewhere around the world. It references to the Trolley Problem, the famous thought experiment provided by Philippa Foot in 1967, an experiment posing a question that is still heavily debated among scholars (Bauman et al. 2014; Scruton 2014; JafariNaimi 2018: is it morally justifiable to kill one person in order to save several others?) This specific quote about "an exciting day", however, is actually not taken from a professional context, but from the episode "The Trolley Problem" (S02E05) of the Netflix television series The Good Place (2016-2020), created by Michael Schur.

The Good Place explains the thought experiment accurately, including some of its variations and problems, but also suggests-throughout its four seasons-a solution to the moral dilemma of the rampaging trolley: self-sacrifice. The only morally "logical" solution to the Trolley Problem is throwing yourself in front of the vehicle, forcing it to stop or to slow down, while warning the workers about the imminent danger. This solution is acted out throughout the series when the protagonists freely choose to sacrifice themselves for the greater good.

The Good Place itself, while being designated as "a comedy", leans heavily on the implementation—both implicitly and explicitly—of ethical concepts, notions and problems, serving as a "classroom" for both its characters and its audiences (Moore 2020; Benko and Pavelich 2020; Yuko 2019; Gutoskey 2019). Ethical dilemmas are the bread and butter of the show in general, the Trolley Problem being one of the most prominent ones. 
To fathom the depth and usability of this proposed solution to Foot's original problem, which the show is championing, we need, in this article, to assess a sequence of steps to clarify what could otherwise turn into a conceptual nightmare. First of all, we need to understand that the notion "Trolley Problem" can refer to at least three different but nevertheless interrelated ideas: to Foot's original thought experiment, to the complex of other thought experiments based on this original one, and to a narrative locus within contemporary popular culture functioning as a term for moral dilemmas in general (Section 1). Furthermore, some important criticisms of the Trolley Problem are addressed.

The same careful approach needs to be taken regarding this article's other constitutive element, the notion of self-sacrifice (Section 2), precisely because it too functions in a "mixed zone" of popular culture and academic philosophy. We need to establish its functioning in popular culture, philosophy in general, in moral philosophy specifically, in the philosophical context of the Trolley Problem itself and in a narrative complex known as the "Drawbridge Keeper", which is thought to combine Foot's experiment with the notion of self-sacrifice. Next, our main case study, The Good Place, will be introduced, focusing on the specific episode of the Trolley Problem, and on the implementation of self-sacrifice in the series' narrative (Section 3). At the end, we will discuss if and how the notion of self-sacrifice can (or cannot) be used as a solution to the Trolley Problem in all three of its forms (Section 4).

\section{The Trolley Problem in Philosophy and Popular Culture}

The Trolley Problem is the brainchild of the English philosopher Philippa Foot (1920-2010). In her seminal article "The problem of abortion and the doctrine of the double effect" (1967), Foot presents several thought experiments, all revolving around the question whether it is morally permissible to save one individual or group by harming other one(s). Foot discusses a judge who can save the community from rioters by convicting and executing an innocent man, and a pilot who has to choose whether to steer his crashing plane into more or less inhabited areas, before formulating what would be known in history as the "Trolley Problem":

He is the driver of a runaway tram which he can only steer from one narrow track on to another; five men are working on one track and one man on the other; anyone on the track he enters is bound to be killed.

In the subsequent development of several versions of Foot's experiment, teasingly dubbed "trolleyology" (Edmonds 2014, pp. 10-11), the philosopher's initial use of the experiment was broadened significantly, up until the point where the trolley and its driver are thought to be the expression of a kind of stand-off between consequentialism (or more specifically utilitarianism) and deontology (Greene 2010, p. 362). The utilitarian driver-assuming doing nothing means running into the five-is thought to decide to save the many over the one by switching tracks. The deontological driver is, however, thought to do nothing and run over the five, since killing one is worse than allowing five to die.

Numerous alternating versions of the Trolley Problem have been constructed. I will treat some of them concisely, because of their adaption in The Good Place, next to its original form. The American philosopher Judith Thomson introduced in her 1976 article called "Trolley Problem" the so-called "Fat Man" scenario. In this case, a bystander is given the choice of stopping the trolley before it hits the five workers by pushing a rather large person in front of it, stopping it in its tracks, but killing the unfortunate human obstacle. In this article, Thomson also gave Foot's original experiment its "popular" form: the tram is switched for a trolley, and the role of the decision-maker is given to a bystander instead of the driver.

In another article, inconveniently also called "The Trolley Problem" Thomson (1985), Thomson introduces new variations, among which are the "Fat Villain" and the "Transplant". In the first one, the philosopher asks if the situation would change if a villain were to have started the trolley rolling towards the five, instead of the events being an accident. Furthermore, in the second one, she introduces the case of a surgeon, who is an expert in organ transplants. He is confronted with five patients in 
dire need of transplant organs and one very healthy young man with completely compatible organs, who is accidentally in the hospital for a yearly check-up. Is it permissible, Thomson asks, to harvest his organs even after he has refused to voluntarily do so?

And in 1992, another American philosopher, Peter Unger, introduced yet another version mentioned in The Good Place, the "Man in the Yard". In this variation, an empty trolley is barreling down a track. The first option is doing nothing: the trolley will crash into six innocents further down the tracks. The second option is to arrange to have another empty trolley head on a collision course with the first one: the six will be saved, but the first trolley will kill a yard owner, lying asleep in his hammock.

All variations of the Trolley Problem try to provoke reflection upon the moral permissibility of one or more possible choices within the thought experiment, by tweaking the different parameters involved, like intention, (intended and/or actual) cause(s), (in)action and so forth, investigating the depth and width of moral philosophy. However, at the same time, the Trolley Problem has also been criticized. The Trolley Problem, and its many versions or rather the ones constructing and discussing them, are accused of moral reductionism. As the British philosopher Roger Scruton (2014, p. 92) stated: "These 'dilemmas' have the useful character of eliminating from the situation just about every morally relevant relationship and reducing the problem to one of arithmetic alone." Other criticisms include the caricaturizing of the utilitarian position (JafariNaimi 2018), and the far-fetched nature of the experiments, dislodging them from everyday life (Bauman et al. 2014, p. 540)

The rise of "trolleyology" resulted in the Trolley Problem leaving the exclusive realm of academic philosophy, for the complex world of popular culture, where it gained fame for the masses, but lost some of its original philosophical finesse. The Good Place is not the only or even first novel, film or series to (implicitly or explicitly) feature the Trolley Problem. Explicit references can be found in the Unbreakable Kimmy Schmidt episode "Kimmy and the Trolley Problem!" (S03E12), the Stargate Atlantis episode "The Game" (S03E15), the film After the Dark (also titled The Philosophers) directed by John Huddles (2013), and in the "Special Screening: A Look Inward" side mission of the game Persona Q2 (2018). The problem is also the primary concern in the "The greater good" episode (S02E01) of the popular scientific YouTube show Mind Field, hosted by Michael Stevens. ${ }^{1}$

Implicit references to the Trolley Problem are said to be found in the Orange is the new black episode "Tied to the tracks" (S05E08) (Upadhyaya 2017), the third season of The Walking Dead series (2012-2013) (Iryna 2017), the third season of Torchwood (2009) (Schmidt 2015), the Kobayashi Maru test from the Star Trek franchise (Stemwedel 2015), the movies Sophie's Choice, directed by Alan Pakula (1982) (Mui 2018), and Terror. Ihr Urteil, directed by Lars Kraume (2016) (Richter 2016) and in The Hunger Games novels by Suzanne Collins $(2008,2009,2010)$ and its film adaptions $(2012,2013,2014$, 2015) (Plantinga 2018, p. 37).

This intertextual and intermedial process of referencing and associating (Allen 2000; Elleström 2010) causes the Trolley Problem to lose its explicit and exclusive connection to Foot's original thought experiment, morphing into a common place for moral dilemmas in general. The same applies to The Good Place, as we will see later in this article. The series invokes both Foot's original experiment, as well as the popular adaption of the notion as a general term for moral dilemmas. Discriminating between Foot's version, its later philosophical adaptions and its (explicit) occurrences in popular culture, is therefore important, as I have stated above. To do so, I suggest a working definition of the Trolley Problem, including not only Foot's original but also the many philosophical variations discussed above.

1 In a rather strange twist of fate, the film Meet me in St. Louis (1944) featured Judy Garland singing the actual "Trolley Song", the lyrics of which include: "Clang, clang, clang went the trolley/Ding, ding, ding went the bell/Zing, zing, zing went my heart strings/From the moment I saw him I fell." Maybe Philippa Foot was inspired by Garland's song in naming her famous thought experiment, maybe not, but I am not the first to teasingly address this odd coincidence (Joyce 2015; Edmonds 2014). 
Based on Foot's description of the original thought experiment of 1967, a moral conundrum could be successfully identified as such if (a) the decision-maker is not in danger himself, (b) the problem is not created by the decision-maker and/or the other ones involved, (c) refusing to play the game is impossible and (d) the options are unequal in quantity and/or quality, while (e) ethically being more or less equally viable. In contrast, in popular culture, an "alleged" Trolley Problem usually involves a difficult choice between (quantitative and qualitative) different individuals or groups of individuals, with severe and/or lethal consequences for one or more of the persons involved, usually including the decision-maker personally. To summarize: the original experiment tries to exclude the decision-maker's personal involvement in the events, while in popular culture the decision maker is usually very much personally involved in the event.

\section{Self-Sacrifice in Philosophy and Popular Culture}

While the concept of self-sacrifice is not as complex as that of the Trolley Problem, here we also have to establish some conceptual clearness. First, we should distinguish between the self-sacrificial hero of our Western narrative complex (Bosman 2019, pp. 97-81), the religiously inspired martyr (Streete 2018), the equally religiously inspired suicide terrorist (Bloom 2005), the committer of "traditional" suicide (Joiner 2005) and those who request and are helped to die in various forms of euthanasia (Pool 2000).

As Moshe Halbertal (2012, pp. 1-2) explained, the term "sacrifice" itself also denotes at least three interconnected ideas: the gift from a human to a godhead, the giving up of something vital for a higher cause, and the victim of a crime. In combination with the notion of the "self", self-sacrifice combines Halbertal's three meanings. The "sacrificer" gives up something vital for something higher. Since this "something vital" is usually, but not necessarily, the sacrificer's own life, the violent ending of one's life makes him/her into a victim of a crime, either committed by others or by the sacrificer him-/herself. Even the divine connotation is preserved in the notion of self-sacrifice, since the act of freely giving up your own life is part of a kind of transaction between the sacrificer and a higher power, may it be anonymous "fate", a (personal) deity, a concept (like "country" or "justice") or just those who are incidentally placed in a more powerful position (Bubbio 2014, p. 1).

The act of self-sacrifice is, however, not without its moral problems in and of itself. As Jeff McMahan pointed out to David Edmonds (2014, p. 195), the Kantian view, for example, prohibits treating a human —any human—as a mere means to an end, including oneself. However, as Edmonds writes, "no philosopher-Kantian or otherwise—wants to say that it is impermissible to kill oneself intentionally for the sake of others."

In the context of this article, for all means and purposes, we presuppose self-sacrifice to refer exclusively to the following situation. Self-sacrifice occurs when someone (a) saves one or more persons, either an individual, a group of individuals or a collective, (b) from a certain, possibly self-inflicted evil, either personal, institutional or abstract in nature, (c) by actually or symbolically giving up his/her own life, (d) out of his/her own free will. The actualization of the offering is not necessary to qualify self-sacrifice as just, but the preparedness and willingness to do so is. Not all self-sacrificial actions require the actual death of the "hero", but they can also be defined as the giving up of something (or someone) symbolically perceived as of equal importance, like the definite loss of the relationship with a love interest or a loved one.

Despite the prominence of self-sacrifice in our cultural narratives, moral philosophers have "surprisingly little to say about the nature of sacrifice" (Van Ackeren and Archer 2018). In the context of care ethics, sacrifice and self-sacrifice have played an important role (Jagger 1991), but this approach has also been criticized by feminists for stimulating women to behave in an altruistic fashion, hindering their own interests (MacKinnon 1987; Hampton 1993). Tessman (2018) warns that self-sacrifice can, for specific individuals, become perceived as obligatory, especially when they are confronted with conflicts of values and moral dilemmas.

Even though Tessman does not mention it, the Trolley Problem comes to mind as being such a case. Even more, self-sacrifice has been brought up in relation to the Trolley Problem. In a 2008 article, 
Thomson (again!) suggests that the bystander in her rendering of the famous experiment has actually three, and not two, possibilities: (1) do nothing and let the trolley kill five, (2) flip the switch to the right, killing one, but saving five, and (3) flip the switch to the left, killing himself, but saving the five. Thomson uses this third option to disqualify diverting the trolley to the track with the one worker or the fat man scenario: sacrifice can only be given, not presumed (and taken).

Taken to the test, a majority of test subjects judge they should either kill the one or sacrifice themselves, if given that option (Huebner and Hauser 2011). Furthermore, Di Nucci (2012) found evidence that participants are more likely to reject the option of killing the one, when they were previously exposed to Thomson's trilemma.

When discussing the combination between the Trolley Problem and the theme of self-sacrifice, especially in the context of popular culture, there is one intertextual complex in which both are tied strongly together: the so-called "myth of the drawbridge-keeper". This myth has numerous variations, has some strong similarities with Foot's experiment and is not infrequently interpreted in overtly Christian terms.

The complex can be traced, at least, to a story from an 1884 book called Railway adventures and anecdotes, compiled by Richard Pike (1884). Long story short: a Russian switch-tender has to choose between doing his job or rescuing his child who is playing on the tracks. Leaving his post would seriously jeopardize the lives of the train passengers. The father shouts out to the child to lie down between the rails and it survives.

A similar story is found in the poem "The drawbridge-keeper" by the American poet Henry Abbey, as a part of his Ballads of good deeds, and other verses (Abbey 1872, pp. 20-22), but with an opposite outcome. In this version, a drawbridge-keeper named Drecker has to choose between his son, who has fallen into the river and is unable to swim, or to maintain his post to assure the safe passage of the train. This time the father is not so clever: he chooses to remain at his post, saving the train, but letting his child drown.

Later, the story was interpreted in Christian terms as an allegory of God letting his son die on the cross for the benefit of humankind. Such an interpretation is found, for example, in the short story "To sacrifice a son. An allegory", first published in 1967 (quoted in Flatten 2009, p. 44). The same happens in the short 1978 film "The Sacrifice" (also known as 'The Bridge'), directed by Robert N. Hatch. Here also a father chooses to save a train full of unknowing passengers instead of his child, who is running on the tracks. In subsequent years the film was acquired by numerous religious organizations for missionary purposes (as claimed by the script-writer of the film on his YouTube channel, see youtu.be/Z-JZ6Nc5UsY).

Furthermore, the 2003 Czech film Most ("The Bridge"), directed by Bobby Garabedian, featuring a by now very well-known scene, has been interpreted in terms of divine sacrifice. In a YouTube montage of fragments from Most, a YouTuber called "thechurchtoolsmedia" (see Available online: youtu.be/BjSio8jur2Y (accessed on 8 May 2012).), explicitly connects the film's theme to that of John 3:16: "For God so loved the world, that He gave His only begotten Son, that whoever believes in Him shall not perish, but have eternal life" (NASB translation). The same explicit connection between the drawbridge-keeper and the quote from John is also drawn by Flatten (2009, p. 44).

While self-sacrifice and the Trolley Problem have some common ground in popular culture and in (moral) philosophy, the intersection between the two has not been thoroughly analyzed. It is in The Good Place that this intersection is explicitly addressed.

\section{3. "The Good Place" on the Trolley Problem and Self-Sacrifice}

\subsection{Introducing the Series}

The Good Place is an American fantasy comedy television series, created by Michael Schur (also known for his work on The Office series), which aired from 19 September 2016, to 30 January 2020 on NBC. Since then, the series, consisting of four seasons and 53 episodes of $22 \mathrm{~min}$ each, has been distributed 
on Netflix internationally in several territories, and as DVDs by the Shout! Factory. Internationally the series has received positive acclaim, both by audiences and by film critics (Poniewozik 2018; Scherer 2018; Adams 2017; Palumbo 2017).

The series' premise is based on the existentialist play Huis Clos (Mellor 2018), written by the famous French philosopher Jean-Paul Sartre in 1944 (Sartre 1989). In "Whenever you are ready" (S04E13), the series' final episode, the two main characters, Eleanor and Chidi, drink coffee in a café at the authentic Place Jean-Paul Sartre and Rue Simone de Beauvoir in Paris. In The Good Place, a small number of people arrive in what appears to be the afterlife, visualized, in the final French setting, as a drawing room in the style of the French Second Empire from Huis Clos, and, in the American setting, as a small suburban town (Berk 2020). In both cases, the, respectively, three or four new arrivals realize-some more quickly than others-that they have not arrived in heaven (or "The Good Place"), but have been doomed to live in hell ("the Bad Place"), where they are supposed to torture each other psychologically for eternity (Cox 2009, p. 138).

In The Good Place, four deceased humans are brought to an afterlife version of American Suburbia, neighborhood $12358 \mathrm{~W}$, or just "The Good Place", where they join 314 other supposedly morally very high-standing people to enjoy everlasting bliss as a reward for their extraordinary lives on earth. The four main characters, however, are not "good people". Two of them know they do not belong in The Good Place: Eleanor Shellstrop (Kristen Bell), a selfish Arizonan woman whose greatest achievement was selling fake drugs to the elderly, and Jason Mendoza (Manny Jacinto), a childish and foolish amateur DJ from Florida. The other two are (very undeservingly) convinced they are in the right place: Chidi Anagonye (William Jackson Harper), a brilliant but extremely indecisive professor of moral philosophy, and Tahani Al-Jamil (Jameela Jamil), a wealthy but self-absorbed British philanthropist.

Right after Eleanor has arrived in "The Good Place" and is welcomed as a hallmark of humanity by Michael (Ted Danson), the neighborhood's architect, she thinks she is a victim of mistaken identity. She is, however, too scared to come clean to Michael. Every time Eleanor makes a mistake, getting drunk, lying, bullying people and so forth, the neighborhood suffers through a sequence of disasters, such as sinkholes or animal stampedes, all not very compliant with the idea of some sort of heavenly place. Eleanor believes it is her fault that The Good Place is collapsing on itself and turns, desperately, to Chidi in confidence and, later on, for ethical lessons in order to improve her overall morality. Later on, the other two, Tahani and Jason, join in.

Eventually, at the end of season one, Eleanor realizes the four are actually not in The Good Place, but in its hellish counterpart, the Bad Place, and unmasks Michael as not a heavenly architect, but a high-ranking demon, who has constructed this neighborhood as part of an elaborate innovation in human torturing: to build a place where bad people would torture each other psychologically for hundreds, if not thousands of years, just like in Sartre's play. Michael's plans fail, because of Eleanor's shrewdness and because of the collective and individual moral improvements brought about by Chidi's ethic lessons to the group.

Michael's subsequent 800 plus "reboots" of the project (season 2) also fail: they do not produce other outcomes. Eleanor always asks Chidi for help, which is always given to her, Chidi always teaches the four ethics, and one of them, usually Eleanor, always finds out the truth about their neighborhood. For the humans, each reboot feels fresh, since Michael erases their memories before. Eventually, Michael is blackmailed by another demon called Vicky (Tiya Sircar). Shawn (Marc Evan Jackson), a Bad Place ringleader, has forbidden more than one reboot, criticizing Michael's ideas for being too fancy and progressive to his liking. Michael joins forces with the four humans to trick Shawn and Vicky into believing the project is still up and running.

At the end of season 2, Michael and the four humans travel through the actual Bad Place to the almighty Judge of earth, heaven and hell, and plead their cases before a woman called Gen (Maya Rudolph). Although the infallible point-system of the afterlife calculated they should spend their eternities in hell, they have showed moral improvement while being in their afterlife neighborhood. The Judge agrees to an experiment in which the previous lives of the four are restored (and their 
memories erased again) to see if they continue to improve themselves while once again living on earth (season 3). Eventually, the four find each other with some secret help from Michael, while being hindered (in vain) by some cheating demons.

When Michael unintentionally reveals the truth concerning the afterlife and the point-system to the four humans, their capacity to gain (or lose) any moral points is lost, since their motivation has become corrupted: they will do good not for good itself but for the selfish motivation of entering the (real) Good Place. Nevertheless, another experiment is granted to Michael and the four by the Judge (season 4): to build another neighborhood, with four new freshly deceased people, to see if they too will improve. Through unsavory (but clever) manipulation by the Bad Place, the experiment is jeopardized. It is only in the end that the four find a way to convince the Judge that the point-system itself is flawed, since it allows no room for improvement after the initial verdict. It is only after this that Michael and the four may access the real Good Place.

During the course of the four seasons many moral philosophies and philosophers are discussed through Chidi's lessons, through discussions among the five main characters, books and chalkboards: from Socrates, Plato and Aristotle to Immanuel Kant, David Hume, Jeremy Bentham and Thomas Scanlon, treating-among others-virtue ethics, deontology, consequentialism (especially utilitarianism) and even moral particularism. The show even had its own philosophical advisors (Adams 2020), moral psychologist Pamela Hieronymi (University of California) and political philosopher Todd May (Clemson University), both appearing briefly in the show's finale "When you are ready" (S04E13) when they discuss philosophy with Chidi. Hieronymi even refers to the Trolley Problem and its particular use in the season 2 episode with the same title: "Bring ponchos. It gets messy."

Even though the series features notions from both the Christian theological traditions, like heaven, hell, a divine judge, demons and the human soul (Mayward 2020), as well as Buddhist concepts like karma, the intertwinement of the individual's actions from one rebirth to the next, samsara, the endless cycle of rebirths itself and nirvana, the release from this cycle into blissful nothingness (Kaur and Gupta 2020), The Good Place presents an ethical-atheist version of the human afterlife. Neither the demon-turned-good-guy Michael, nor Gen the Judge have the characteristics of a classic deity: they are superhumanly powerful and intelligent, but not at all omnipotent or all-knowing.

In the very first episode "Everything is fine" (S01E01), Eleanor asks Michael "who was right" concerning the afterlife. Michael answers in a pluralistic fashion: "Well, let's see. Hindus are a little bit right, Muslims a little bit. Jews, Christians, Buddhists, every religion guessed about 5\%." And when Chidi and Eleanor finally experience The Good Place at the end of season 4 ("When you are ready"), Chidi tells a well-known Buddhist metaphor:

For spiritual stuff, you gotta turn to the East. Picture a wave in the ocean. You can see it, measure it, its height, the way the sunlight refracts when it passes through, and it's there, and you can see it, you know what it is. It's a wave. And then it crashes on the shore, and it's gone. But the water is still there. The wave was just a different way for the water to be for a little while. That's one conception of death for a Buddhist. The wave returns to the ocean, where it came from, and where it's supposed to be.

Other references to the Christian (or Buddhist for that matter) theological tradition are scarce. In "When you are ready"' the four are told that—finally—-the great medieval philosopher and theologian "Saint Thomas Aquinas" has entered The Good Place. Moreover, in "The eternal shriek" (S01E07), one of Chidi's flashbacks brings him to the lecture room of his friend and colleague Henry (no surname), who also features in the Trolley Problem episode. On Henry's chalkboard the subject of his lecture can be seen: "Philosophy 322: Eschatology and notions of the Apocalypse". On the board, there are some theological reading suggestions, Alan Segal's Life after death (Segal 2004), Jürgen Moltmann's The coming of God (Moltmann 2005), Brian Daley's The hope of the early church (Daley 2010) and Jeffrey Russell's Paradise mislaid (Russell 2006), all famous theological works on-indeed-the concept of the 
Christian afterlife. Chidi however, never quotes or discusses any theological or religion-related topics in his classes.

\subsection{The Episode "The Trolley Problem"}

The episode "The Trolley Problem" (S02E05), aired on 19 October 2017, was written by Josh Siegal and Daylan Morgan, and directed by Dean Holland. It takes place at the end of the first half of season two. Michael has just reluctantly joined the four humans in an effort to save his own skin from Vicky's ambition and Shawn's wrath. Fellow-demon Vicky is blackmailing Michael: if he does the not turn over leadership of the neighborhood to her, she will tell Shawn that Michael's project and leadership are failures. Shawn, in his turn, will eliminate Michael in a very painful manner as soon as he finds out the truth about the neighborhood's 800 plus reboot failures.

Eleanor is the most skeptical of the four in joining forces with a demon, but is more or less overruled by the other three and by the insight that there, after all, is no better (or even other) option to reach The Good Place. Therefore, the four accept Michael's offer to help them enter the real Good Place in return for their assistance. Eleanor's conditio sine qua non, however, is that Michael should join "Team Cockroach", as the four were, in a demeaning manner, called earlier, and participate in Chidi's ethical lectures. He reluctantly agrees, but his heart is definitely not in it yet, and he frequently sabotages the lessons to the frustration of Eleanor and Chidi ("Team Cockroach" S02E04). When Michael is forced into an existential crisis and works his way through a mini-midlife crisis ("Existential crisis" S02E05), he appears to be a little bit more prepared to put some effort into the ethical lessons, although he is still "not getting it".

This becomes apparent when Chidi introduces the group to the Trolley Problem (S02E06). The blackboard gives away the most important details of this ethical lesson, listing not only Foot (1967), but also some of the variations on the Trolley Problem developed by Thomson (1976), Coast (1987) and Unger (1992). Prominent on the board is the focus-point of Foot's original thought experiment: "deontology versus utilitarianism". Chidi introduces the Trolley Problem by describing Foot's experiment, to which Eleanor and Tahani react in favor of killing the one worker to save the five.

Then, Chidi makes the experiment more complex by adjusting some details, like the familiarity with the one or the five workers, or the ethical difference between controlling the trolley (as Foot suggested) or being a bystander as in (Thomson 1985) version. He also introduces Thomson's surgeon (Thomson 1985). Tahani replies with "that is not the same thing". Chidi provocatively replies "Why not? It's still choosing to kill one person to save five, isn't it?" probing right into the heart of the problem's subject matter.

Michael has his own opinion about the solution to this ethical dilemma: "How do you kill all six people? So, I would dangle a sharp blade out the window to slice the neck of the guy on the other track as we smush our five main guys." It appears to be quite an effort for a demon learning human ethics: Chidi makes him write "people = good" on the back of his blackboard. After the lesson, Chidi confronts Michael with his homework, a comment on Victor Hugo's classic novel Les Misérables. Michael writes condescendingly about the characters-they are all French which makes them doubly more likely to end up in the Bad Place: "I know for a fact that if you steal a loaf of bread, it's a negative 17 points." Michael—unknowingly—utilizes a (simplified) deontological argument: stealing is always wrong, whatever the circumstances, which are-as we know-severe for the characters in the novel.

Michael is frustrated by the fact that Chidi will not tell him what the right answer to the Trolley Problem is. Chidi on his part, tries to explain that the principal insolvability of the problem is at the heart of the thought experiment: it makes clear that one and the same moral problem can be approached from different angles and can be evaluated accordingly. Michael rebuffs him: "This is why everyone hates moral philosophy professors." This line is something of a running gag in the series. The same joke is made in "Everything is Bonzer" (S03E01), twice in "The Eternal Shriek" (S01E07) and once by Chidi himself in "Rhonda, Diana, Jake, and Trent" (S02E10). 
Michael, echoing a common criticism against the Trolley Problem being too abstract and theoretical in nature, demands a more hands-on situation. With a snap of his finger, he transforms the classroom into a real-life simulation, in which he, Eleanor, and Chidi find themselves on a busy street at the wheel of an actual runaway trolley. The situation is as in Foot's original experiment: Chidi is at the controls of the trolley and can choose to run into either five or one worker(s) on the tracks.

Demonstrating yet another possible flaw of the Trolley Problem (the theoretical endless amount of time available to ponder the dilemma), Chidi has ample time to react, but before he can make any conscious decision, the trolley runs over the five workers, splashing the moral philosophy professor with blood and small body parts. This is, again, a perfect demonstration of the theoretical nature of the thought experiment. That is why Pamela Hieronymi in the show's finale (S04E13) warns her students: "Bring ponchos. It gets messy." Michael confirms this by saying: "They're fake people, but their pain is real. Does that make sense? There have to be stakes, or it's just another thought experiment."

Chidi, understandably, is very angry over what has happened to him and lashes out at Michael. When the demon defends himself by saying he was asked by Chidi to connect more with the training material, the teacher and pupil are, temporarily, reconciled. This does not hinder Michael in restarting the simulation, but altering it slightly, swapping the anonymous one worker for one of Chidi's academic friends, Henry. At first, Chidi is confident and switches tracks-"I can do this. I am choosing to switch tracks, so that way, I only kill one person"-but when he sees Henry on the track, he tries to warn him to step away.

Henry is not only totally unaware of the imminent danger, he is unable to move, since one of his very red cowboy boots has got stuck in the track. (This is an in-show reference to an earlier situation, when Chidi was still alive, and failed to honestly tell his friend Henry how he felt about his hideous boots, ending up receiving a pair from Henry, which he felt obliged to wear immediately). Needless to say, Henry also ends with a splash, on Chidi.

In the next scene, we see-again—a blood-covered Chidi on the trolley, while Michael is taking notes: "Okay, so that was Trolley Problem version number seven. Chidi opted to run over five William Shakespeares instead of one Santa Claus." Unfortunately, the other five scenarios remain unspecified, but they are certain to deal with various modifications of the original problem. Michael seems satisfied with what he has learned, and switches to another famous variation, described by, again, Thomson (1985).

This "problem number seven" is a light-hearted reference to the criticism given to the Trolley Problem (see above). The experiment pits two groups against each other, one to die, the other to live. The decision-maker is given more and more rare and often purely theoretical groups to choose from. The Good Place takes this criticism to the next level by proceeding with it in absurdum: nowhere in the world one could be asked to choose between five Shakespeares and one Santa Claus, since the first is dead and quite unique, while the second one is an imaginative character.

Michael, Eleanor and Chidi are-appropriately dressed-in an operating theatre, where five patients lie motionless on surgical tables, overlooked by an interested audience. Michael explains: "These five people all need organ transplants, or they will die. Eleanor's perfectly healthy. Chidi, do you want to slice her open and use her organs to save the five sick people?" Again, like in Henry's case, the "five" are unknown, while the "one" has an emotional relationship with the "decider", that is, Chidi.

Chidi is again confident, as in the second scenario, and refuses to sacrifice one person to save five: "I won't do it. As a doctor, I've taken the Hippocratic Oath to do no harm, and although five people will die, I cannot harm one innocent person to save them and forsake my oath. It's unethical." Michael is satisfied and asks Chidi to inform the family. With a snap of his finger, the three are confronted with the sorrow-ridden family of the five patients, all eagerly awaiting the doctor's decision to proceed with saving their loved ones. One child approaches Chidi and asks: “Doctor Chidi? My daddy needed a heart transplant. Did you save his life? He was working, then a really bad man ran him over with a trolley." 
The connection between the first and the last version of the Trolley Problem-Chidi refusing to save one of the workers who was brought into mortal danger because of Chidi's choice not to switch tracks-reveals a certain hidden truth to Eleanor, namely that Michael is still psychologically torturing them: "You don't care about learning ethics lessons. You're just torturing Chidi again, aren't you?" Michael acknowledges this frankly: "I'm sorry. Old habits die hard. Not as hard as those people you crushed with the trolley, though. Boom!" Understandably, Chidi is offended by Michael's behavior and throws him out of the study group. Only after some heart-felt apologies, is Michael allowed back in again.

\subsection{The Theme of Self-Sacrifice in the Series}

The Trolley Problem is mentioned four times in the series, besides this episode. One has already been mentioned: in the series' finale, Professor Hieronymi refers explicitly to the "Trolley Problem." The second one is when Jason formulates his very private interpretation of Foot's experiment ("You've changed, man", S04E10): "One of your boys sets off a stink bomb on the trolley, causing a commotion so the rest of the group can pickpocket people as they run off the train." We can leave this for what it is.

The third and fourth times are more significant to our investigation, especially in connecting the Trolley Problem to the theme of self-sacrifice. When Shawn declares Michael's experiment a success ("Leap of Faith", S02E08), not knowing that the four humans have joined forces with their former torturer, he is invited to a "roast" with Chidi, Eleanor, Tahani and Jason in front of all the other demons, who have played the roles of the other inhabitants of neighborhood $12358 \mathrm{~W}$. While the four humans are unsure as to which side Michael is on —he is really doing his best during the roast-Michael inserts secret hints into his jokes to help them escape their departure to the "real" Bad Place. When Michael roasts Chidi, he says:

"Speaking of Chidi" is something no one has ever said, because no one talks about Chidi, because no one likes Chidi, because he's so annoying about ethics. Now, when you taught the Trolley Problem, did you secretly wish that it could be you who wound up under the trolley? Because all your students did.

Michael hints at an insight, formerly impossible for any demon to have had: could self-sacrifice be the solution to the Trolley Problem? This insight is made explicit two episodes later. When Michael contrives a plan to cross the real Bad Place-the demons' offices- to enter the realm of Gen the Judge, he needs five official pins (depicting a thumb pointing downwards) to be able to pass the through portal between the two places ("Rhonda, Diana, Jake, and Trent", S02E10). After much ado, he still only has four pins. Chidi, Tahani and Jason have already passed through the portal into the Judge's office, safe from the demons in the Bad Place, but Eleanor lacks hers. Then Michael grabs her shoulders and says:

Hey, guess what? I just solved the Trolley Problem. Remember? The thought experiment where you're driving the trolley, and you can either plow into a group of people or turn and hit one person? I solved it.

Eleanor is not very appreciative at that moment, but Michael insists:

See, the Trolley Problem forces you to choose between two versions of letting other people die. And the actual solution is very simple. Sacrifice yourself.

Then, Michael attaches his own pin to Eleanor's breast, giving her his own passage to safety. Even though she tries to resist Michael's actions, he flings her through the portal, while Shawn and a couple of other demons close in on him. Michael has not only found a "solution" to the Trolley Problem, a problem earlier deemed unsolvable in principle by Chidi, but he executes this solution immediately, pushing both the problem and the solution from the purely theoretical domain into the real world. Later, Eleanor explicitly identifies Michael's actions as such: "He sacrificed himself to save me" ("Burrito", S02E11). 
The theme of self-sacrifice is very prominently featured in the series, both explicitly and implicitly: Eleanor, Chidi and Michael are identified as making self-sacrifices multiple times. I want to address some examples, four from before Michael's pin-swapping, and four from afterwards. The first explicit instance occurs when Michael (still pretending to be a Good Place's architect) addresses the neighborhood because of the "unexplained" disasters taking place ("Eternal Shriek", S01E07). Chidi is bursting with anxiety, since he thinks Eleanor's insincerity is causing the mayhem. Before his principles get the best of him, Eleanor comes clean and confesses she does not belong in The Good Place, unknowingly jeopardizing Michael's whole enterprise. Episodes later, when Michael has already joined the team, he identifies, in retrospect, Eleanor's behavior as a self-sacrifice: "You saw your friend in pain and you decided to sacrifice yourself to help him."

In "What's my motivation" (S01E11), the subject is raised twice. Tahani tries to help raise Eleanor's moral score by doing good deeds, but since the latter's motivation is corrupt—she wants to do good to gain some personal benefit instead in benefit of the other-her attempts remain in vain. When Eleanor loses hope, Tahani tries to elevate her spirit: "Look, I know this is tedious, but ( . . ) all the big-ticket items are impossible, I'm afraid. It's not as if you could, you know, 'sacrifice your life to save others' (italics are mine) or 'change the consciousness of a nation'." This is however, precisely what Eleanor will do, multiple times during the series, and even within the one and the same episode.

When (still secretly "bad") Michael tells the four that (super-demon Shawn posing as) "the Judge" is arriving by train, Eleanor decides to take the train to the Bad Place herself in order to save Chidi and Tahani (whom they still, incorrectly, believe do belong in The Good Place). Her motivation: "You have to be a good person to stay here, and I can't become a good person unless I leave". Eleanor, instead, flees to a newly discovered "Medium Place", where the forces of good and evil cannot reach her ("Mindy St. Clair", S01E12).

Michael in the meantime, dishonestly, tries to defend Eleanor's behavior before "the Judge" by claiming her deed was an act of self-sacrifice: "she was sacrificing herself because she is a wonderful, selfless..." The Judge agrees with him initially ("Yes, voluntarily sacrificing herself and heading to the Bad Place would be a point in her favor"), but contrasts this qualification by pointing out that she has actually fled to the Medium Place for selfish reasons. (All this is of course part of Michael's master plan to let the four humans psychologically torture each other.)

When "the Judge" gives an ultimatum-Eleanor has to turn herself and Jason, who accompanied her, in to him or he will take Chidi and Tahani to the Bad Place-she decides to do what she initially intended: she returns to Michael and "the Judge" to bargain for the lives of her friends. "The Judge" refuses to stick to his deal, because Eleanor and Jason were just seconds too late and suggests another gambit: since the Bad Place "owes" two slots, the four humans can discuss among themselves who can stay and who has to go. It is in this chaos that Eleanor figures out the true nature of the events and unmasks Michael and "the Judge" as torturing demons ("Michael's Gambit", S01E13).

After the four humans have entered the Judge's office, leaving demon-turned-good-guy Michael in the Bad Place, they are tested to see if they have indeed grown so much morally that they could be allowed into the real Good Place ("Burrito", S02E11). All four are confident they will succeed, since they have experienced their ethical growth. Three of them fail however: Tahani cannot control her wish to know what other people think of her, Jason (forced to play against his favorite team on a game console) does not understand that not playing is also an ethical option, and Chidi is still so indecisive that it takes him hours to choose from two almost identical and meaningless hats to wear. Eleanor on her part, succeeds in her test.

When a "fake" version of Chidi encourages her to leave without Tahani and Jason (who failed their tests), she refuses, identifying her friend as an apparition conjured up by the Judge. When Eleanor finds out she is the only one that has grown enough to enter The Good Place, leaving her three companions to the real Bad Place, she refuses again to go alone. Even though Eleanor has just sacrificed her own eternal well-being twice in a very short amount of time, the series does not mention this any further, neither is Eleanor rewarded for her behavior in any explicit way. 
When the real Judge initiates a new experiment-sending the four back to Earth-to live their lives as if nothing ever happened, Chidi falls in love with his colleague Simone (a reference to the French philosopher Simone de Beauvoir), while Eleanor (Chidi's long-lasting love interest) stands by and even encourages the two to hook up ("The Ballad of Donkey Dog", S03E05). The series does not qualify this as a self-sacrifice, which indeed it is not since neither Chidi nor Eleanor have memories of them falling in love in their "bad" neighborhood. However, from the point of the audience of the series, who are well informed of their history together, this could easily be perceived as such.

Eventually, when the four humans discover the afterlife point-system which prevents every attempt at improving their lives any further, since their motivation has become corrupt, Chidi breaks up with Simone out of fear he will "spill the beans" to her and corrupt her motivation to be good too ("The Snowplow", S03E05). This is also not explicitly acknowledged by the series as a self-sacrifice, but it qualifies as such, nevertheless.

Again, a new experiment is conducted with the Judge's permission (since the last one failed on technicalities). Michael develops a new neighborhood in the Medium Place, this time with four new humans to repeat the first scenario in which Tahani, Jason, Chidi and Eleanor were ethically improving ("Chidi Sees the Time Knife", S03E12). The Bad Place interferes with the experiment, resulting in the peculiar situation that Chidi and Simone are two of the "new" experiment's candidates. However, if this new set-up is to work, Chidi has to allow his memories to be erased again, forgetting his romantic relationship with Eleanor (again) and will probably (again) be attracted to Simone ("Pandemonium", S03E13).

To make things even more complicated, Michael suffers a mental breakdown, forcing Eleanor to pose as the neighborhood's architect. This puts her in the position to actively encourage (again) Chidi and Simone to develop a bond, since Chidi's moral philosophy lectures to the group are at the core of the experiment's first and (hopefully) second experiment ("A Girl from Arizona", part 1, S04E01).

This complex situation requires from both Chidi and Eleanor an act of self-sacrifice. Eleanor has to sacrifice her long-lasting love interest, possibly for eternity, while actively trying to bond Chidi with her competitor Simone; and Chidi reluctantly but willingly sacrifices his, possibly eternal, romantic relationship with Eleanor for the benefit of the old and the new human groups. When Eleanor is initially somewhat hesitant to introduce Chidi and Simone, Michael reminds her of what Chidi has done: "I know it's painful to think of the two of them connecting, but Chidi made an incredible sacrifice."

Eleanor echoes this qualification (in "A Girl from Arizona", part 2, S04E02): "Chidi made a huge sacrifice for us, and I had to make sure it was worth it." Michael in his turn, focusses attention on Eleanor's actions, calling it an even bigger self-sacrifice: "It's arguable that you made an even bigger sacrifice. You actually have to live with this situation. Chidi just gets to go around blissfully unaware of what he gave up."

Eventually, when Michael is accused of being a stand-in from the Bad Place, ordered to tamper (again) with the experiment, he volunteers to "blow himself up": "That way, you can continue the experiment with Chidi as one of the people, which is our best chance to ever be successful" (S04E04). Eleanor refuses, but is comforted at the same time. By offering to kill himself, Michael has proven he is "legit". Eleanor: "You offered to sacrifice yourself to help a bunch of cockroaches. That's about the most Michael thing you could do."

This is the last explicit occurrence of the theme of self-sacrifice in the series, although not the last implicit one. When the four humans (and Michael) have successfully found their way into the real Good Place ("Patty", S04E12), they find out that being in "heaven" for literally eternity is not a good thing after all. Hence, Michael—having been promoted to head architect of The Good Place - constructs a "door" through which one can walk, in order to end his or her life indefinitely. First, Jason goes through the door, while Tahani studies to become an architect herself. Then, Chidi, after what appears to be eternity, himself makes his wish known to go through the door. Eleanor tries to persuade him not to do so, but eventually she yields: 
I proposed a rule that Chidi shouldn't be allowed to leave because it would make Eleanor sad, and I could do this forever, zip you around the universe showing you cool stuff, and I'd still never find the justification for getting you to stay. Because it's a selfish rule. I owe it to you to let you go.

This is the final self-sacrifice of the series: to let your loved one go because you love them. It is also a reference to the book What we owe to each other by American philosopher Thomas Scanlon (1998), which popped up regularly throughout the four seasons. Scanlon's contractualism demands, with regard to our theme of self-sacrifice: "If we can prevent something very bad from happening to someone by making a slight or even moderate sacrifice, it would be wrong not to do so" (Scanlon 1998, p. 224).

The question to be answered here is how we qualify Eleanor's final act of self-sacrifice: as "slight" or "moderate", or as severe? I would argue the last qualification, since The Good Place will cease to be as soon as Eleanor is there without "her" Chidi. It is ironic that a series of YouTube lectures by Chidi on precisely this book at the start of season three, and which brought Eleanor and Chidi together (in their continuous lives on Earth), now demands of her to release him into the void.

\section{Self-Sacrifice as a Solution to the Trolley Problem}

Let us return to the idea, suggested by The Good Place, that self-sacrifice is the solution to the Trolley Problem. As Michael claimed: "See, the Trolley Problem forces you to choose between two versions of letting other people die. And the actual solution is very simple. Sacrifice yourself." To contemplate this suggested solution, I want to address it on three different levels: (a) on the level of the Trolley Problem in the strict sense (Foot's original experiment, including Thomson's later adjustments), (b) on the level of the Trolley Problem understood as the complex of moral thought experiments inspired by Foot's original one, and (c) on the level of the Trolley Problem as it is used in popular cultural narratives, especially in The Good Place.

On the level of Foot's original experiment, the solution of self-sacrifice is, I would argue, at least technically, plausible. The experiment leaves room for the possibility of the tram's driver to throw himself in front of the vehicle, thus slowing it down enough to eradicate the necessity of making a choice between the five and the one. The same applies to the bystander in Thomson's rendering of Foot's experiment: he/she can also be thought of as "throwing oneself under the bus", so to speak. This scenario approaches, however, that of Thomson's Fat Man scenario, since we can presume that the weight of either the driver or the bystander would be enough to slow down the vehicle at the cost of the sacrificer's life.

If we understand the complex of all the thought experiments based on Foot's as a stand-off between consequentialist and deontological systems of morality, the option of self-sacrifice appears ambivalent. From a consequentialist point of view, there is — ethically speaking — not that much difference between the two possibilities both ending with one dead and six alive (either the five and the bystander or the five and the one). From a deontological viewpoint, the self-sacrifice is difficult to assess morally, since the moral imperative demands universal rulings, usually including not killing anyone. Even if we allow for the fact that the killing of one can result in one or more others remaining alive, the act itself remains problematic.

One of the experiments belonging to the Trolley Problem Complex, is Thomson's scenario of the surgeon and his patients. This scenario is the only one, besides Foot's original one, to be explicitly featured in The Good Place. How would self-sacrifice function in this scenario? Probably, by the surgeon him-/herself volunteering to be used as the donor saving the five patients. However, there are some potential problems to overcome: the surgeon has to be the perfect biological match for the patients, as the one healthy man is in Thomson's set-up; and if the surgeon agrees to be operated on, there would be no one left to do the operation. Of course, if we let our minds wander off, we could conjure up another doctor, almost as good as the original, self-sacrificing one, but this changes the experiment too drastically to stay within the original parameters. So, self-sacrifice does not seem to be an option here. 
Let us now turn to the setting of The Good Place: if Michael claims he solved the Trolley Problem by sacrificing himself, what does he mean? The first problem we have to face is conceptual. Does Michael's predicament qualify as a Trolley Problem, either in the stricter or less strict sense? I argue it does not, and that complicates matters much. The decision-maker (Michael) is not neutral to the situation; it concerns him very personally. He is also personally (but maybe partly) responsible for their predicament: he was the architect after all. Besides, the two possible options he can choose from, fleeing and leaving Eleanor in the Bad Place or vice versa, are equal in quantity and quality: one is saved, one is not.

To what problem is self-sacrifice the answer, if not to the "classic" Trolley Problem? The answer becomes clearer if we interpret Michael's Trolley Problem as a general denotation of moral dilemmas in popular culture, as I have already done earlier in this article. The problems the many self-sacrifices in The Good Place are "solving" are usually moral dilemmas involving two options, one more or less altruistic and one more or less egoistic. The problem is always of personal relevance to the decision-maker. Furthermore, the altruistic option always comes at a (very) high cost for the one choosing it. $^{2}$

For example: Eleanor speaking up, before Chidi's morals get the better of him, is an altruistic choice, but condemns her to the Bad Place, so she believes. Michael's pin-swapping is also an altruistic deed, but also dooms him to the Bad Place, where he will be treated very unkindly for his treason. Eleanor turning herself in to the Bad Place saves-potentially-her three friends, but severely jeopardizes the quality of her (eternal) life. Eleanor's lying about passing her test, dooms her for remaining loyal to her friends.

Additionally, last but not least, Eleanor's agreement to let Chidi's memory be erased, and her helping him bond with Simone, is beneficial not only for the four humans and Michael, but potentially for all human beings in the past, present and future, since a positive outcome of the experiment could lead to an enormous increase in those who are welcomed to The Good Place. Yet, it is at a great price, losing the love of her life, with the same love destroying The Good Place for her when he decides to leave it after some part of eternity.

Essentially, The Good Place tries to make three points concerning the Trolley Problem, as long as we accept its more generous and more universal meaning of being a moral dilemma in general.

(a) When confronted with a moral dilemma in general, self-sacrifice is always an option, if not practically possible (like in the case of the surgeon), then at least as a true consideration. Telling others and yourself that a moral dilemma is "just not your responsibility" is not an option, according to the The Good Place. Of course, this has ramifications for Foot's driver or Thomson's bystander.

(b) Self-sacrifice is only true and authentic if, and when, given freely and altruistically. Forcing someone to give up his life or a significant interest, for example a love interest, is still a sacrifice, but not a self-sacrifice. The "self" is indicative of both the sacrifice's object-that what is given-and of the sacrifice's subject-who is giving. That is why it has to be unselfish or altruistic: if such a sacrifice were to be predominantly beneficial to the one bringing it, it ceases to be a sacrifice as such. When Eleanor tries to earn points for the afterlife by doing good deeds in her postmortem neighborhood, she fails because her motivation is "corrupt", that is "self-centered".

(c) Together with Scanlon, The Good Place affirms that self-sacrifice is morally not only justifiable but could even be regarded as one's moral duty. In this, the series goes beyond Scanlon's original contractualism, which only demands a "slight or moderate sacrifice". In The Good Place, the sacrifice is total, a sacrifice of the self. However, even when and if self-sacrifice is a moral obligation, as the series seems to suggest, that does not make it someone else's moral (or legal or practical) right to be given.

2 The notion of "altruism" is in and of itself not without conceptual problems of its own. Critics have argued that true altruism cannot exist, since it defies rational self-interest, and has long-term and/or indirect (perceivable) positive "pay-back", ultimately undercutting the essence of altruism itself (Hwang and Bowles 2012). While this is certainly true, in the course of this article, I will ignore this topic because of practicality. In this article, we will assume that all acts designated as altruistic are, indeed, unproblematically perceived as such by all individuals involved in and effected by it. 
Self-sacrifice can only be given out of moral obligation or other reasons but cannot be demanded. To paraphrase Scanlon, what we owe each other is not the same as what we demand of each other. Again, the idea of self-sacrifice as a duty is a direct violation of the voluntarist nature of the deed itself.

The Good Place is indeed a moral laboratory for its characters and its audiences, reflecting the fundamental moral values of humankind, while discussing all its problematic actualizations, problems and dilemmas. In the end, it presents a very high moral standard: to sacrifice oneself if that is beneficial to one or more other people. In its radicalism, The Good Place's message is not very unlike the Christian interpretation of the narrative complex of the Drawbridge Keeper. That is, to say the least, a remarkable conclusion to draw from The Good Place as a whole.

As I have shown earlier on, The Good Place does use religious aesthetics and rhetoric, especially from Christian and Buddhist traditions, as set pieces for its "afterlife mechanisms", but refrains from explicitly addressing religious concepts of the afterlife (with some minor exceptions). The afterlife The Good Place is constructing is of an ethical, secular and ultimately atheist nature. It comes as more than a surprise to conclude that this secular show ultimately arrives at a solution for the Trolley Problem that depends on the religious, and especially Christian, notion of self-sacrifice.

In a larger perspective, this might be explained by the notion that the Christian tradition, including its heavy emphasis on the virtue of self-sacrifice of all believers and its idea of Christ's self-sacrifice on the cross as being beneficial to all of humankind, has been and still is a very strong cultural influence, working its way-implicitly-into secular and contemporary, "post-Christian" series such as The Good Place. While the series may refrain from addressing explicit Christian beliefs on the afterlife, its core message of self-sacrifice as a solution for a moral dilemma is Christian in nature nevertheless.

Funding: This research received no external funding.

Conflicts of Interest: The authors declare no conflict of interest.

\section{References}

Abbey, Henry. 1872. Ballads of Good Deeds, and Other Verses. New York: D. Appleton \& Company.

Adams, Erik. 2017. The Good Places. The Uncommonly Decent TV Worlds of Michael Schur. AV Club. September 21. Available online: https:/www.avclub.com/the-good-places-the-uncommonly-decent-tv-worlds-of-mic1818561418 (accessed on 28 April 2020).

Adams, Sam. 2020. The Two Philosophers Who Cameoed in The Good Place Finale on What They Made of Its Ending. Slate. February 3. Available online: https://slate.com/culture/2020/02/the-good-place-finale-endingexplained-philosopher-cameos-analysis.html (accessed on 28 April 2020).

Allen, Roland. 2000. Intertextuality. London: Routledge.

Bauman, Christopher, Peter McGraw, Daniel Bartels, and Caleb Warren. 2014. Revisiting External Validity. Concerns about Trolley Problems and Other Sacrificial Dilemmas in Moral Psychology. Social and Personality Psychology Compass 8: 536-54. [CrossRef]

Benko, Steven, and Andrews Pavelich, eds. 2020. The Good Place and Philosophy. Get an Afterlife. Chicago: Open Court.

Berk, Kiki. 2020. Is hell other people? In The Good Place and Philosophy. Get an Afterlife. Edited by Steven Benko and Andrews Pavelich. Chicago: Open Court.

Bloom, Mia. 2005. Dying to Kill. The Allure of Suicide Terror. New York: Columbia University Press.

Bosman, Frank. 2019. Gaming and the Divine. A New Systematic Theology of Videogames. London: Routledge.

Bubbio, Paolo. 2014. Sacrifice in the Post-Kantian Tradition. Perspectivism, Antisubjectivism, and Recognition. Albany: State University of New York.

Coast, Michael. 1987. Another trip on the trolley. The Southern Journal of Philosophy 25: 432-79. [CrossRef]

Cox, Gary. 2009. Sartre and Fiction. London: Continuum.

Daley, Brian. 2010. The Hope of the Early Church. A Handbook of Patristic Eschatology.. Grand Rapids: Baker Academic.

Di Nucci, Ezio. 2012. Self-sacrifice and the Trolley Problem. Journal of Philosophical Psychology 26: 662-72. [CrossRef] 
Edmonds, David. 2014. Would You Kill the Fat Man? The Trolley Problem and What Your Answer Tells Us about Right and Wrong. Princeton: Princeton University Press.

Elleström, Lars. 2010. The modalities of media. A model for understanding intermedial relations. In Media Borders, Multimodality and Intermediality. Edited by Lars Elleström. New York: Palgrave/Macmillan.

Flatten, Alfred. 2009. In It for Life. A Spiritual Roadmap on the Quest for Discipleship. Mustang: Tate Publishing and Enterprises.

Foot, Philippa. 1967. The Problem of Abortion and the Doctrine of the Double Effect. Oxford Review 5: 5-15.

Greene, Joshua. 2010. The secret joke of Kant's soul. In Moral Psychology. Historical and Contemporary Readings. Edited by Thomas Nadelhoffer, Eddy Nahmias and Shaun Nichols. Malden: Wileu-Blackwell.

Gutoskey, Ellen. 2019. 5 Moral Philosophy Concepts Featured on The Good Place. Mental Floss. September 26. Available online: https://www.mentalfloss.com/article/600054/the-good-place-moral-philosophy-concepts (accessed on 28 April 2020).

Halbertal, Moshe. 2012. On Sacrifice. Princeton: Princeton University Press.

Hampton, Jean. 1993. Feminist Contractarianism. In A Mind of One's Own. Feminist Essays on Reason and Objectivity. Edited by Louise M. Antony and Charlotte Witt. Boulder: Westview Press.

Huebner, Bryce, and Marc Hauser. 2011. Moral judgments about altruistic self-sacrifice. When philosophical and folk intuitions clash. Journal of Philosophical Psychology 24: 73-94. [CrossRef]

Hwang, Sung-Ha, and Samuel Bowles. 2012. Is altruism bad for cooperation. Journal of Economic Behavior E Organization 83: 330-41.

Iryna, Sonya. 2017. Maggie's Ethical Dilemma about Keeping Prisoners of the Walking Dead. Undead Walking. November 28. Available online: https://undeadwalking.com/2017/11/28/walking-dead-maggie-prisonershilltop/ (accessed on 28 April 2020).

JafariNaimi, Nassim. 2018. Our Bodies in the Trolley's Path, or Why Self-driving Cars Must *Not* Be Programmed to Kill. Science, Technology, \& Human Values 43: 302-23.

Jagger, Alison. 1991. Feminist ethics projects, problems, prospects. In Feminist Ethics. Edited by Claudia Card. Lawrence: University Press of Kansas.

Joiner, Thomas. 2005. Why People Die by Suicide. London: Harvard University Press.

Joyce, Daryl. 2015. Crossing Over. Carlsbad: Balboa Press.

Kaur, Kamalpreet, and Meenu Aggarwal Gupta. 2020. Hinduism gets more than five percent right. In The Good Place and Philosophy. Get an Afterlife. Edited by Steven Benko and Andrews Pavelich. Chicago: Open Court.

MacKinnon, Catharine. 1987. Feminism Unmodified. London: Cambridge University Press.

Mayward, Joel. 2020. Heaven is other people. In The Good Place and Philosophy. Get an Afterlife. Edited by Steven Benko and Andrews Pavelich. Chicago: Open Court.

Mellor, Louisa. 2018. The 1944 Existentialist Play That Inspired The Good Place. Den of Geek. August 4. Available online: https://www.denofgeek.com/culture/the-1944-existentialist-play-that-inspired-the-goodplace/ (accessed on 28 April 2020).

Moltmann, Jürgen. 2005. The Coming of God. Christian Eschatology. London: SCM Press.

Moore, Rose. 2020. The Good Place: 10 Best Life Lessons Eleanor Taught Us. Screen Rant. February 23. Available online: https://screenrant.com/the-good-place-eleanor-shellstrop-life-lessons/ (accessed on 28 April 2020).

Mui, Chunka. 2018. 3 Ways the Trolley Problem Distracts from Solving the Bigger Human Driver Problem. Forbes. October 29. Available online: https://www.forbes.com/sites/chunkamui/2018/10/29/3-waysthe-trolley-problem-distracts-from-solving-the-bigger-human-driver-problem/\#6c0f8bfa14e0 (accessed on 28 April 2020).

Palumbo, Stephanie. 2017. 'The Good Place's Optimism Is a Salve for Despair in the Trump Era. Vulture. January 25. Available online: https://www.vulture.com/2017/01/the-good-places-optimism-is-a-salve-for-despair-in-thetrump-era.html (accessed on 28 April 2020).

Pike, Richard. 1884. Railway Adventures and Anecdotes. Extending over More than Fifty Years. London: Hamilton, Adams, and Company.

Plantinga, Carl. 2018. Screen Stories. Emotion and the Ethics of Engagement. Oxford: Oxford University Press.

Poniewozik, James. 2018. How 'The Good Place' became an antihero antidote. The New York Times. January 21. Available online: https:/www.nytimes.com/2018/01/31/arts/the-good-place-kristen-bell-ted-danson.html (accessed on 28 April 2020).

Pool, Robert. 2000. Negotiating a Good Death. Euthanasia in the Netherlands. London: Routledge. 
Richter, Linda. 2016. Dieses Gedankenexperiment sollten Sie vor Ihrem Urteil kennen. Stern. October 18. Available online: https://www.stern.de/kultur/tv/trolley-problem----terror--ihr-urteil--7107516.html (accessed on 28 April 2020).

Russell, Jeffrey. 2006. Paradise Mislaid. How We Lost Heaven, and How We Can Regain It. New York: Oxford University Press.

Sartre, Jean-Paul. 1989. No Exit and Three Other Plays by Jean Sartre. New York: Vintage Books. First published 1944. Scanlon, Thomas. 1998. What We Owe to Each Other. Cambridge: Bellknap Press of Harvard University Press.

Scherer, Jenna. 2018. How 'The Good Place' Turned into the Smartest, Funniest Sitcom on TV. Rolling Stone. February 2. Available online: https://www.rollingstone.com/tv/tv-news/how-the-good-place-turned-intothe-smartest-funniest-sitcom-on-tv-121942/ (accessed on 28 April 2020).

Schmidt, Maria. 2015. Doctor Who's Impossible Choices and the Trolley Problem. Doctor Who TV. February 23. Available online: http://www.doctorwhotv.co.uk/doctor-whos-impossible-choices-and-the-trolley-problem71985.htm (accessed on 28 April 2020).

Scruton, Roger. 2014. Parfit the perfectionist. Philosophy 89: 621-34. [CrossRef]

Segal, Alan. 2004. Life after Death. A History of the Afterlife in the Religions of the West. New York: Doubleday.

Stemwedel, Janet. 2015. The Philosophy of Star Trek: The Kobayashi Maru, No-Win Scenarios, and Ethical Leadership. Forbes. August 23. Available online: https://www.forbes.com/sites/janetstemwedel/2015/08/23/ the-philosophy-of-star-trek-the-kobayashi-maru-no-win-scenarios-and-ethical-leadership/\#292ba5b65f48 (accessed on 28 April 2020).

Streete, Gail. 2018. Performing Christian martyrdoms. In Martyrdom, Self-Sacrifice, and Self-Immolation. Religious Perspectives on Suicide. Edited by Margo Kitts. Oxford: Oxford University Press.

Tessman, Lisa. 2018. Sacrificing Value. International Journal of Philosophical Studies 26: 376-98. [CrossRef]

Thomson, Judith. 1976. Killing, letting die, and the Trolley Problem. The Monist 59: 204-17. [CrossRef] [PubMed]

Thomson, Judith. 1985. The Trolley Problem. The Yale Law Journal 94: 1395-415. [CrossRef]

Unger, Peter. 1992. Causing and preventing serious harm. Philosophical Studies 65: 227-55. [CrossRef]

Upadhyaya, Kayla Kumari. 2017. Orange Is the New Black Recap. Manatees versus Sharks. Vulture. June 16. Available online: https://www.vulture.com/2017/06/orange-is-the-new-black-season-5-episode-8.html (accessed on 28 April 2020).

Van Ackeren, Marcel, and Alfred Archer. 2018. Self-sacrifice and moral philosophy. International Journal of Philosophical Studies 26: 201-307. [CrossRef]

Yuko, Elizabeth. 2019. The Good Place Isn't just a Funny Show-It Can Actually Help Make You a Better Person. Thrive Global. March 7. Available online: https://thriveglobal.com/stories/the-good-place-nbc-lessons-betterperson-empathy-productivity/ (accessed on 28 April 2020).

(C) 2020 by the author. Licensee MDPI, Basel, Switzerland. This article is an open access article distributed under the terms and conditions of the Creative Commons Attribution (CC BY) license (http://creativecommons.org/licenses/by/4.0/). 